\title{
The Role of Strategic Human Capital Management in Achieving the Competitive Advantage ${ }^{1}$
}

\author{
Mlle. Bouguesri Sarra Assistant Master
}

Faculty of Business and Economy (University of Mascara) E-Mail:sara9002007@yahoo.fr

\section{Dr. Djilali Benabou}

Faculty of Business and Economy (University of Mascara- Algeria) E-Mail : djbenabou@yahoo.fr

\section{Dr. Habib Tabeti}

Faculty of Business and Economy (University of Mascara- Algeria) E-Mail : h_tabeti@maktoob.com

Doi:10.5901/ajis.2013.v2n3p361

Abstract

These days Human Capital is considered most important element of competitive advantage in most organizations. In is just one of the organisation's intangible assets; it is basically all of the competencies of the people within an organization. These competencies are various skills, education, and experience, potential and capacity. It is believed that if a company know how its human capital contributes to their success, it than can be measured and managed effectively. Developing human capital in the organisation is the major challenge for the leaders for formulating future competitive strategies. "Dynamic and complex competitive landscape has created considerable uncertainty for firms, however conditions of uncertainty also present opportunities" (Hitt et al 1998). Organizations are increasingly looking at human resources as a unique asset that can provide sustained competitive advantage. The changes in the business environment with increasing globalization, changing demographics of the workforce, increased focus on profitability through growth, technological changes, intellectual capital and the never ending changes that organizations are undergoing have led to increased importance of managing human resources. The importance of human capital to play role in gaining competitive advantage is greater than ever before because of it is crucial wealth, success and competitive advantage of the organisation. "To create workforce that provide competitive advantage the firms create environment that provide knowledge, motivation, engagement that would be difficult for competitors to imitate" (Afioni 2007; Agarwal \& Ferret, 2001; Luftman \& kempaiah 2007). This research investigate the role of strategic management human capital that allow the Algerian companies to achieve the competitive advantage among a case study in different Algerian companies.

Keywords: Human capital- Case study-Algerian companies -Competitive advantage. Code JEL : 19

\section{Introduction}

These days Human Capital is considered most important element of competitive advantage in most organizations. In is just one of the organisation's intangible assets; it is basically all of the competencies of the people within an organization. These competencies are various skills, education, and experience, potential and capacity. It is believed that if a company know how its human capital contributes to their success, it than can be measured and managed effectively. Developing human capital in the organisation is the major challenge for the leaders for formulating future competitive strategies. "Dynamic and complex competitive landscape has created considerable uncertainty for firms, however conditions of uncertainty also present opportunities" (Hitt et al 1998). "The competitors of the firm always try to employ better peoples

${ }^{1}$ This study is carried out under the National Research Program: knowledge economy and knowledge management for sustainable development. 
for the job, so firms should constantly evaluate the human factor. (Eric D. brown 2007) he also concluded that the ability to create unique team is the most cost effective ways to create sustainable advantage". The way in which the organizations manage its peoples can influence its performance (Peter \& Watermann 1982). "The employee participation, empowerment and job design, including team based production system, extensive employee training and performance contingent incentive are widely believed to improve the performance of organisation" (Pfeffer 1994). "The strategic human resources management or the human capital is mean of gaining competitive advantage through one of the most important asset: its people" (Richard W 2001). According to Ulrich (1998), a major role of HR personnel is to become a strategic business partner.

Singh (2003) gives a broader approach to looking at strategic human resources management (SHRM) by integrating various functions and establishing the linkage of these functions with the business plan. It is important not only to identify HR competencies in concurrence with the business needs and to develop selection and development practices to secure those competencies, but also to evolve and implement a performance evaluation plan that links the performance of the employees to the strategic goals. (Riham Darwish Mustafa Najia,2008)

This paper focus to delineate the role of strategic human resource management in achieving the competitive advantage in Algerian companies .

\section{Literature of Review}

Many research shows that that it is through the human resource capital pool (here replaced with tacit knowledge and the knowledge creation process) and employee behavior that human resources can constitute a sustained competitive advantage. Thus, managers can implement human resource practices that can positively impact the knowledge creation process and, as a result, the strategic goals of the firm. A manager can use human resource practices such as developmental assignments, formal training opportunities, and compensation to create new tacit knowledge and new explicit knowledge, and to reduce tacit knowledge loss by reducing employee turnover. Given the dynamic environment and the criticality of knowledge workers, firms must have human resource practices that promote continuing skill development. Figure 1 illustrate how through the human resource management as source of sustained competitive advantage.

Figure 1: A Model of Human Resource Management as a source of Sustained Competitive Advantage

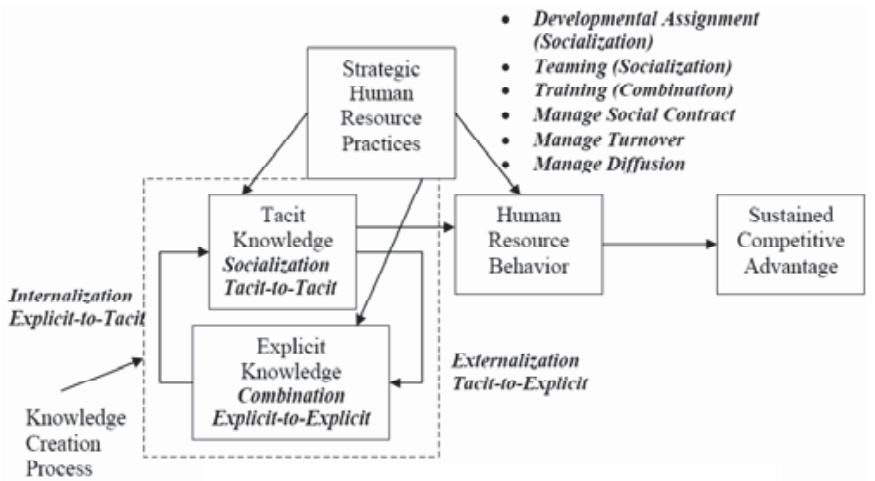

Source: Knowledge Worker: Human Resource Strategy to Achieve a Competitive Advantage Doctorial Student Richard L. Jayne

The human factor in the strategies of organisation has long been ignored, in the recent times it has gained importance and the leadership of the organisation began to realize that the human factor is critical in the creating and sustaining the competitive advantage. Many studies suggest that the human capital should be considered in the formulation level of the organizational strategy.(Peck 1994, Scarpello 1994, Schuler et al 1993) describe the need to convert the human resources of an organisation into a competitive advantage implies that humans factor should be equal partner in both formulation and implementation of organisation's competitive strategy. According to (Stone 1998) whenever an organisation formulates it strategy, it requires identification, analysis and balancing of its internal strength and 
weaknesses and external threats and opportunities. This interpretation is about the overall strategy of organisation but many researcher who support RBV are agree that much attention should be given to internal resources and particularly human capital. (Greer ,1995) argue that human factor serve as driving force in strategic formulation, the organisation need to built their strategies on human based capabilities for the competitive advantage.(Sharma \& Khanedekar 2006) describe the vitality of human factor in environment scanning and providing information about the internal strength and weaknesses. Human capital are an important source of competitive advantage, it can augment the organisation's competitive advantage through cost leadership and differentiation. (Porter 1980) believe in focusing on the innovation, quality enhancement and cost reduction in the human capital to gain competitive

advantage.(Terpstra \& Rozell 1993) found that organisation with human resources practices and performance had higher levels of annual profits, growth and overall performance than those with less sound practices. (Pfeffer 1994) identified 16 human resources practices that, in his opinion, can enhance an organisation's competitive advantage. (Richard \& Johnson 2001) "In a study suggested that strategic effectiveness significantly reduces employee turnover and increase overall market performance. They also recommended that the strategic HR effectiveness affected both productivity and return on equity. (M. Memon, R.Mangi and C. Lal Rohra,2009)

The following figure shows how we can make a strategy with the human capital

Figure 2: Human Capital Strategy Model

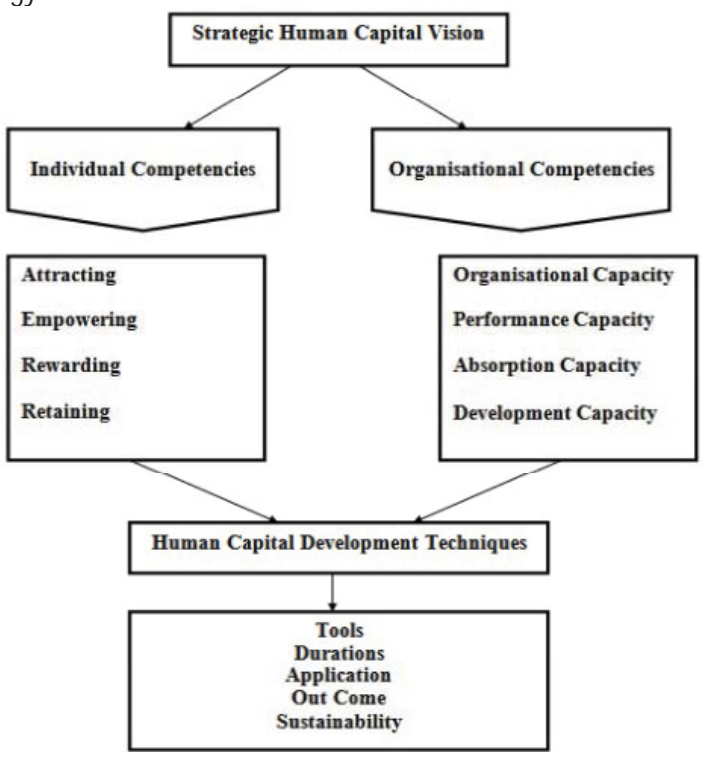

Source: M. Memon, R.Mangi and C. Lal Rohra : Human Capital a Source of Competitive Advantage "Ideas for Strategic Leadership", Australian Journal of Basic and Applied Sciences, 3(4): 4182-4189, 2009,p 4185

\subsection{Strategic Human Resource Management}

SHRM involves the development of a consistent, aligned collection of practices, programs (strategies), and policies to facilitate the achievement of the organization's strategic objectives (Mello, 2002).

The SHRM literature is rooted in "manpower" planning, but it is the work of influential management experts (e.g., Ouchi, 1981) affirming the importance of the effective management of people as a source of competitive advantage, that encouraged academics to develop frameworks emphasizing the strategic role of the HR function (e.g., Beer et al., 1985; Fombrun et al., 1984) and attaching the prefix "strategic" to the term "human resource management.

Wright and McMahan's (1992) definition of strategic human resource management illustrates that the main focus of the field should be on integrating HR with firm strategies. Jim Walker's (1980) classic book Human Resource Planning was one of the first to directly suggest considering a firm's business strategy when developing a human resource plan.( S. Davoudi \& K.Fartash , 2012) 


\subsection{Competitive Advantage}

Critical to a corporation's growth and prosperity is gaining and retaining competitive advantage. Although corporations may pursue many paths to this end, one that is frequently not recognized is capitalizing on superior human resource management.

Currently, many companies recognize the growing importance of their human resources, but few are conceptualizing them in strategic terms - in ways to gain a competitive advantage. As a result, many companies forego the opportunity to seize competitive advantage through human resource practice initiatives. However, there are a few companies that do not forego the opportunity.( Riham Darwish . Najia, 2008)

Wright, et al (1994) has shown that human resources meet Barney's criteria for being a source of sustainable competitive advantage. Coff (1994) argues that human assets are a key source of sustainable advantage because of causal ambiguity and systematic information making them inimitable.

\subsection{Human Resource as Source of Competitive Advantage}

The resource-based view suggests that human resource systems can contribute to sustained competitive advantage through facilitating the development of competencies that are firm specific. The sustained superior performance of many companies has been attributed to unique capabilities for managing human resources to gain competitive advantage.

Conversely, to the extent that HR systems inhibit the mobilization of new competencies and/or destroy existing competencies, they may contribute to organizational vulnerability and competitive disadvantage.

HRM needs to achieve the following strategic goals in order for the company to gain and sustain competitive advantage:

- to invest in people through the introduction and encouragement of learning processes designed to increase capability and align skills to organizational needs,

- to ensure that the organization identifies the knowledge required to meet its goals and satisfy its customers and takes steps to acquire and develop its intellectual capital,

- to define the behaviours required for organizational success and ensure that these behaviours are encouraged, valued and rewarded,

- to encourage people to engage wholeheartedly in the work they do for the organization,

- $\quad$ to gain the commitment of people to the organization's mission and values.

To achieve these goals it is necessary to understand the linkage between HRM and business strategy. . ( $\mathrm{S}$. Davoudi \& K.Fartash , 2012)

\section{Empirical Study}

\subsection{Objective and methodology}

The model of this study is translate from the study of S.( Riham Darwish . Najia, 2008) that investigates the role of aspects of Strategic Human Resources Management (SHRM) in the Jordanian Mobile Telecommunications Industry, and their being potential sources of creating company competitive advantage .

The aim of this research is to investigate the role of strategic management human capital that allow the Algerian companies to achieve the competitive advantage among a case study in different Algerian companies. behavior,

We classify human resource management into three aspects : Socialization, Training practices and Human

Socialization: Chao, O'Leary-Kelly, Wolf, Klein, and Gardner developed six content areas for organizational socialization and developed scales to research learning in these areas:

Performance proficiency, language, people, politics, organizational goals and values, and History. (S. Davoudi \& K.Fartash 2012),

- Training practices: by implementing employee training programs, organizations are likely to enhance their chances of developing their employees' learnings which ultimately leads to their chances of achieving better capabilities and productivity as well.

- Human behavior: Human behaviour is very much unpredictable. In behaviour we cannot assume one set 
pattern of behaviour. Lavitt classified behaviour as: (i) Caused behaviour, (ii) Motivated behaviour, (iii) Goal oriented behaviour. From these observations it can be understood that behaviour is a dependent factor. By understanding behaviour one can predict, direct, change and control behaviour of individuals or group. There are generally four basic assumptions regarding nature of people: individual differences, a whole person, caused behaviour (motivation) and value of the person (human dignity).

- Competitive advantage refers to a firm's ability to implement value creating strategies that are not being implemented by any current or potential competitors. Strategies that are rare, inimitable and non-substitutable.

The model proposed is shown in the follow figure :

Figure 3: Proposed relationship between SHRM aspects and competitive advantage

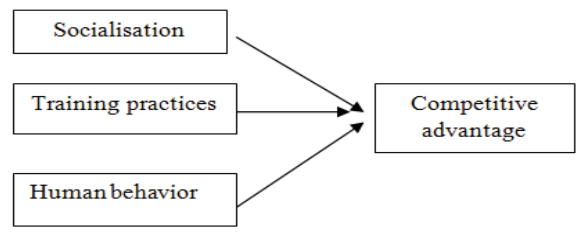

The hypotheses are described as follows:

H1: An organization's socialization activities are positively related to its ability to obtain distinctive resources that develop its competitive advantage

H2: An organization's training programs and activities are positively related to its ability to obtain distinctive resources that develop its competitiveadvantage..

H3: Constructive human behavior of an organization's employees is positively related to its ability to obtain distinctive resources that develop its competitive advantage.

\subsection{Data Collection and Samples:}

This study tested hypotheses with a questionnaire survey that was conducted in Algerian companies. The data for this study was collected throughout a field survey. There were 5 organizations in different sectors in Algeria.

\subsection{Results}

In order to test for the normal distribution of response data, Cronbach's alpha was used to test the reliability of the measures. All variable and sub-variable items were approximately confirmed valid since their factor loading values were more than 0.4 , as shown in the table 1.

Table 1: The test of the reliability

\begin{tabular}{|l|c|}
\hline \multicolumn{1}{|c|}{ Items } & Cronbach's alpha \\
\hline Socialization & 0.543 \\
\hline Training practices & 0.462 \\
\hline Human behavior & 0.531 \\
\hline Competitive advantage & 0.657 \\
\hline
\end{tabular}

Pearson's bi-variate correlation coefficient was used to test the relationship between independent and dependent variables. An ANOVA test was then used to analyze respondents' characteristics related to gender, age, education, role and experience.

The data for the study were collected from 50 respondents from various different services companies. As per the table-2 demographic profiles of the respondents where male participants in the study was 32 where female participants consisted 18 of the total population. The almost of the respondent have the license diploma, it consists $75.8 \%$. Age wise distribution depicts 31-40 age group dominates in the study consisting of more than $46 \%$ of the total sample. The respondents having less than 5 years of experience at current organization is very well present in the study consisting of 
$61.7 \%$ of the total sample.

Table 2: Respondents profile

\begin{tabular}{|c|c|c|c|}
\hline Parameter & Group & $\boldsymbol{N}$ & $\%$ \\
\hline \multirow{2}{*}{ Sex } & Male & 32 & 64 \\
& Female & 18 & 36 \\
\hline \multirow{4}{*}{ Age } & $20-30$ & 18 & 36.7 \\
& $31-40$ & 23 & 46 \\
& $41-50$ & 8 & 16 \\
& $>50$ & 1 & 2 \\
\hline \multirow{3}{*}{ Study level } & Secondary & 1 & 21.7 \\
& License & 42 & 75.8 \\
& Post graduate & 7 & 2.5 \\
\hline \multirow{3}{*}{ Role } & General manager & 4 & 5 \\
& Trade commercial & 10 & 14.2 \\
& Account & 5 & 13.3 \\
& Branch manager & 2 & 15 \\
& Others & 29 & 52.5 \\
\hline \multirow{2}{*}{ Experience } & $>5 y e a r s$ & 23 & 38.3 \\
& $<5$ years & 27 & 61.7 \\
\hline Total & & 50 & 100 \\
\hline
\end{tabular}

Table 3 depicts the mean scores of each variable and its corresponding construct. Generally speaking, all items scored in the affirmative ( 1 = strongly disagree, $5=$ strongly agree, with 3 the mid-point) with mean values greater than 3.0. Only the human behavior is greater than the mean proposed that mean that the respondents are agree with the questions posed of this items.

Table 3: Statistical results of summary variables

\begin{tabular}{|l|c|c|}
\hline & Mean & Std- dev \\
\hline \multicolumn{1}{|c|}{ SHRM } & 2,43 & 1.39 \\
\hline Socialization & 1,77 & 0,89 \\
\hline Training practices & 2,28 & 1.04 \\
\hline Human behavior & 3.26 & 1,12 \\
\hline Competitive advantage & 2,83 & 1.23 \\
\hline
\end{tabular}

The results related to path analysis showed that the three sub-constructs of human resource management have a negative and weak relationship with business performance.

Table 5 represents a correlation matrix across all variables and SHRM values being statistically significant $(p<$ 0.01).

As shown in the table 5 there is a weak and a negative relationship between competitive advantage and socialization and very weak and positive relationship between training practices and human behavior .

Table 5: Correlation matrix

Socialization Training practices Human behavior Competitive advantage

\begin{tabular}{lccc}
\hline Socialization & & & \\
Training practices & -0.103 & 0.255 & \\
Human behavior & -1.89 & 0.054 & 0.488 \\
Competitive advantage & -0.212 &
\end{tabular}

Note: All correlation values are significant at the 0.01 level (two-tailed) 


\section{Discussion}

Our study found that the relationship between socialization and competitive advantage become statistically no significant with weakness relationship . Means that algerian companies haven't a consideration to implement socialization practices within its organization.

There is a weak relationship between training practices and competitive advantage , it is apparent that the Algerian companies in implementing competitive advantage developing training practices within its organization, This means that of the competitiveness in the companies was explained by the human resources behavior factor.

There was a significant relationship between the human resources behavior and developing a competitive advantage, means according to this SHRM aspect (human resources behavior), as it would be relevant and applicable with regards to this specific SHRM aspect. And means that of the competitiveness in the companies was explained by the human behavior factor.

The present research found that there is a weak correlation between the component of strategic human resource management and competitive advantage that mean that meaning that our algerian manager and employer have a weak awareness that to confront face the intense competition, it's important to the companies interest to his competitive advantage.

\section{Conclusion}

In order to formulate appropriate competitive advantage through employees, it is first necessary to analyze the firm's competitive strategy or business strategy and organizational human resource practices. The organization should create a complete model of HRM and employment relationship; also it should support long-term thinking, building "core competencies" and also develop "sensing" capabilities.

For achieving competitive advantage, the role of human capital behavior in the Algerian companies is greater than ever before because it is considered to be the wealth success and major source of competitive advantage.

To the Algerian companies it is recommended that the employer strategy should focus on creating competitive advantage through the employees and using the practices that support this strategy which include:

- Creating an attractive work environment through socialization practices.

- Optimizing people resource levels through constant training and skill development.

- Sharing information.

- Developing capabilities.

- Designing optimal work systems.

- Aligning reward and recognition systems

Finally, Organizations are increasingly looking at human resources as a unique asset that can provide sustained competitive advantage. The changes in the business environment with increasing globalization, changing demographics of the workforce, increased focus on profitability through growth, technological changes, intellectual capital and the neverending changes that organizations are undergoing have led to increased importance of managing human resources, for these raison Algerian companies should had more consideration of the strategy of the human resource management to still alive and competitor with other companies.

\section{References}

E. Mehdi Mousavi Davoudi \& K.Fartash ,(2012) , Integrating human resource management with firm's strategy: A key concept to achieve firm's superior performance, A Journal of Economics and Management, Vol.1 Issue 2, ISSN2278-0629

M. Memon, R.Mangi and C. Lal Rohra.(2009). Human Capital a Source of Competitive Advantage "Ideas for Strategic Leadership", Australian Journal of Basic and Applied Sciences, 3(4): 4182-4189.

Riham Darwish Mustafa Najia(2008), Aspects of strategic human resources management and their role in developing competitive advantage: An Applied Study on the Jordanian Mobile Telecommunications Industry, Master's Degree in Business Administration. Middle East University for Graduate Studies Department of Administrative Sciences .

Schuler, R.P. Dowling and H. Decieri, 1993. "An integrative Framework of Strategic International Human Resources management, International Journal of Human Resource Management, 4: 717-64.

Schuler, R.P. Dowling and H. Decieri, 1993. "An integrative Framework of Strategic International Human Resources management, International Journal of Human Resource Management, 4: 717-64

Sharma, A., A. Khanedkar, 2006 "Influence of HRD Initiatives on Learning in a challenging Environment: A study of Indian Global Corporation. A paper Read at the AHRD International Research Conference February 22-25 Ohio. 
Stone, J., 1998. "Human Resource Management, (Third Edition) Australia: Wiley.

Terspstra, D. and E. Rozell, 1993. "The relationship of Staffing Practice to Organisational Level Measures of Performance. Personnel Psychology, 46(1): 27-48.

Peck, S., 1994. Exploring the link between Organisational Strategy and Employment Relationship: Then Role of Human Resources Management Policies. Journal of management Studies, 31(5): 715-36.

Mello, Jeffrey A. (2002), Strategic Human Resource Management, South-Western Publications Ulrich, D. (1998). A New Mandate for Human Resources. Harvard Business Review, 76 (1): 124

Wright, P., McMaham, G. and McWilliams, A., 1994 "Human Resources and Sustained

Competitive Advantage: A Resource-Based Perspective" Int. J. of HRM, Vol. 5, No 2, pp 301-326. 